\title{
Valor nutritivo da Coastcross-1 inoculada com Azospirillum brasilense
}

\author{
[Nutritive value of Coastcross-1 inoculated with Azospirillum brasilense] \\ P.F. Aguirre ${ }^{1}$, C.J. Olivo², J.C. Sauthier ${ }^{3}$, M.P. Sauter ${ }^{3}$, J.F. Aires ${ }^{3}$, \\ D.C. Seibt ${ }^{l}$, G.D. Simonetti ${ }^{l}$ \\ ${ }^{1}$ Aluno de pós-graduação - Universidade Federal de Santa Maria - Santa Maria, RS \\ ${ }^{2}$ Universidade Federal de Santa Maria - Santa Maria, RS \\ ${ }^{3}$ aluno de graduação - Universidade Federal de Santa Maria - Santa Maria, RS
}

\begin{abstract}
RESUMO
Objetivou-se com este trabalho avaliar a taxa de produção de forragem e o valor nutritivo da Coastcross1, inoculada com Azospirillum brasilense, fertilizada com diferentes doses de $\mathrm{N}$ e submetida ao regime de corte. $\mathrm{O}$ delineamento experimental foi o de blocos ao acaso, com três repetições, em esquema fatorial. Os fatores foram o uso da inoculação (não inoculada, inoculada somente no plantio e reinoculada no segundo ano), níveis de $\mathrm{N}(0,100$ e $200 \mathrm{~kg} / \mathrm{ha} / \mathrm{ano}$ de $\mathrm{N})$ e os períodos do ano. Avaliaram-se a taxa de produção e a composição botânica da forragem, a composição morfológica, o teor de proteína bruta, a digestibilidade in situ da matéria orgânica e os nutrientes digestíveis totais da Coastcross-1. A inoculação, quando não associada ao adubo nitrogenado, ocasionou aumento na taxa de produção de forragem, na participação da Coastcross-1 e na produção de nutrientes digestíveis totais. Houve redução nos teores de proteína bruta da Coastcross-1, quando a gramínea adubada com $200 \mathrm{~kg} / \mathrm{ha} /$ ano de $\mathrm{N}$ foi inoculada. A inoculação tem efeito positivo na Coastcross-1 não submetida à adubação nitrogenada.
\end{abstract}

Palavras-chave: Cynodon dactylon, digestibilidade, nutrientes digestíveis totais, proteína bruta, taxa de produção de forragem

\begin{abstract}
The objective of this study was to evaluate the forage yield rate and nutritive value of Coastcross-1 inoculated with Azospirillum brasilense and fertilized with different levels of nitrogen subjected to cut. The experimental design was randomized blocks with three replications, in a factorial scheme. The factors were the inoculation (without inoculation, inoculated just in the implantation and reinoculated in the second year), levels of nitrogen $(0,100$ and $200 \mathrm{~kg} / \mathrm{ha} /$ year of $N)$ and periods of the year. Forage yield rate and botanical composition; morphological composition, crude protein content, in situ digestibility of organic matter and the total digestible nutrients of Coastcross-1 were evaluated. Inoculation increased the forage yield rate, Coastcross-1 contribution and production of total digestible nutrients, when the pasture was not fertilized with $N$. There was reduction in Coastcross-1 crude protein content when fertilized with 200kg/ha/yr of $\mathrm{N}$. The inoculation has a positive effect on Coastcross-1 not submitted to nitrogen fertilization.
\end{abstract}

Keywords: crude protein, Cynodon dactylon, digestibility, forage yield rate, total digestible nutrients

\section{INTRODUÇÃO}

Em distintos sistemas de produção pecuária, vem ocorrendo aumento significativo do uso de forrageiras perenes, com ênfase para as do gênero Cynodon. Entre as cultivares, a

Recebido em 20 de abril de 2017

Aceito em 21 de dezembro de 2017

E-mail: priscilafloresaguirre2014@gmail.com
Coastcross-1 destaca-se pela elevada produção (Aguirre et al., 2014) e bom valor nutritivo da forragem; essa gramínea é bastante exigente em fertilidade, tendo boa resposta à adubação, principalmente a nitrogenada (Oliveira et al., 2011). Porém, o uso indiscriminado desse tipo de adubação pode elevar o custo de produção, além 
de poder causar danos ao ambiente, pois grande parte do $\mathrm{N}$ aplicado não é aproveitado pelas plantas, podendo ser perdido por lixiviação, volatilização de amônia e desnitrificação. Dessa forma, o emprego de tecnologias que visem à diminuição do uso de adubos nitrogenados, sem perdas na produtividade e no valor nutritivo da forragem, é desejável. Nesse contexto, vem sendo estudada a inoculação de gramíneas com bactérias diazotróficas associativas, como a Azospirillum brasilense, conhecidas também como bactérias promotoras do crescimento vegetal, que, além de fixarem $\mathrm{N}$ atmosférico, produzem fitormônios, responsáveis pelo maior desenvolvimento do sistema radicular, havendo, assim, aumentos significativos na absorção de nutrientes pela planta hospedeira (Hungria et al., 2010). Pesquisas já realizadas com estirpes dessa bactéria têm resultados satisfatórios, principalmente com milho e trigo (Hungria et al., 2010; Lana et al., 2012).

Estudos avaliando a contribuição da inoculação com $A$. brasilense em gramíneas perenes são raros. Assim, este trabalho foi conduzido com o objetivo de avaliar a taxa de produção de forragem e o valor nutritivo da Coastcross-1, inoculada com A. brasilense e submetida a diferentes níveis de adubo nitrogenado.

\section{MATERIAL E MÉTODOS}

A pesquisa foi conduzida em área do Setor de Bovinocultura de Leite, pertencente ao Departamento de Zootecnia da Universidade Federal de Santa Maria (UFSM), situada na Depressão Central do Rio Grande do Sul, no decorrer de dois anos agrícolas, de agosto de 2014 a maio de 2016. O clima da região é o subtropical úmido (Cfa), conforme classificação de Köppen (1948), sendo as normais climatológicas (Fig. 1) de temperatura de $19,2^{\circ} \mathrm{C}$ e precipitação de $140,5 \mathrm{~mm} /$ mês. Para o período experimental, os valores de temperatura média mensal e precipitação pluviométrica foram de $20,5^{\circ} \mathrm{C}$ e $170,9 \mathrm{~mm} / \mathrm{mês}$ (Banco..., 2016). Nesse período foram registradas, na Estação Meteorológica da UFSM, situada a aproximadamente $700 \mathrm{~m}$ da área experimental, 16 geadas, sendo seis em agosto de 2014, sete em junho de 2015, uma em julho de 2015 e duas em setembro de 2015.

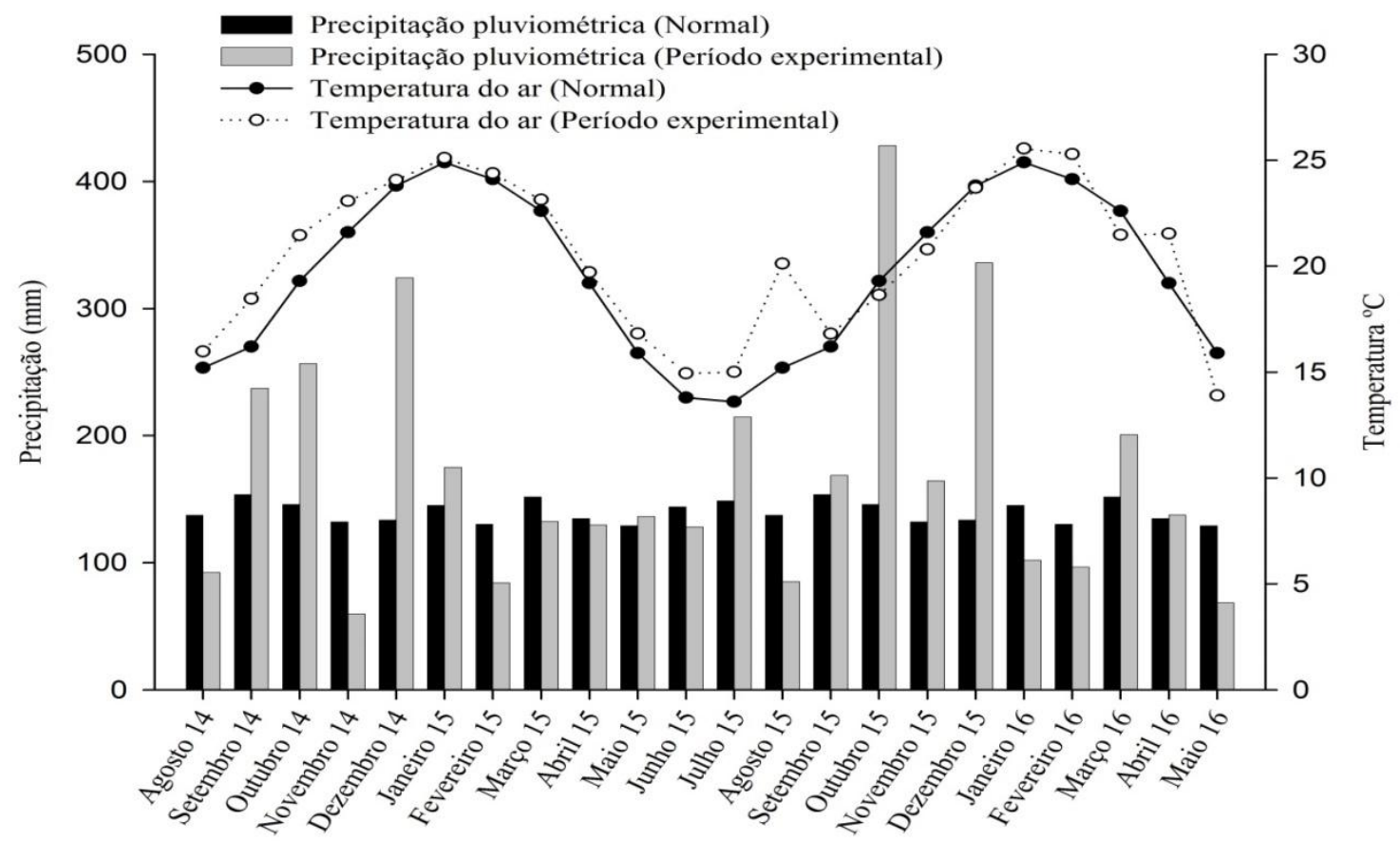

Figura 1. Normais climatológicas e valores registrados no período experimental para temperatura média e precipitação acumulada mensal (Banco..., 2016). 
O solo é classificado como Argissolo Vermelho distrófico arênico (Streck et al., 2008). Na análise de solo $(0-20 \mathrm{~cm})$, realizada antes da implantação do experimento, obtiveram-se os seguintes valores médios: $\mathrm{pH}-\mathrm{H}_{2} \mathrm{O}=5,3$; índice $\mathrm{SMP}=5,7$; argila $=28 \%$; P-Mehlich $=7,6 \mathrm{mg} / \mathrm{dm}^{3}$; $\mathrm{K}=116 \mathrm{mg} / \mathrm{dm}^{3} ; \quad \mathrm{MO}=3,2 \% ; \mathrm{Al}=0,2 \mathrm{cmol}_{\mathrm{c}} / \mathrm{dm}^{3}$; $\mathrm{Ca}=8,2 \mathrm{cmol}_{\mathrm{c}} / \mathrm{dm}^{3} ; \mathrm{Mg}=3,4 \mathrm{cmol}_{\mathrm{c}} / \mathrm{dm}^{3}$; saturação de bases $=65,7 \%$ e saturação por $\mathrm{Al}=1,7 \%$.

Para as avaliações, foi utilizada área de aproximadamente $700 \mathrm{~m}^{2}$, dividida em 27 parcelas, com dimensões de $5 \mathrm{~m}$ de comprimento e $3 \mathrm{~m}$ de largura, cada uma, e corredores de $1 \mathrm{~m}$ de largura entre elas. $\mathrm{O}$ experimento foi constituído por um arranjo fatorial completo, com nove tratamentos, sendo o fator $\mathrm{A}$ (qualitativo) a utilização ou não da inoculação (Coastcross-1 não inoculada; Coastcross-1 inoculada somente no plantio; e Coastcross-1 inoculada no plantio e no segundo ano de utilização), e o fator B (quantitativo) os diferentes níveis de adubo utilizados $(0,100 \mathrm{e}$ $200 \mathrm{~kg} / \mathrm{ha} /$ ano de N).

Aproximadamente 45 dias antes da implantação da Coastcross-1, foi realizada a correção da acidez do solo, com calcário dolomítico, mediante incorporação ao solo, com o auxílio de grade aradora. A adubação de base do primeiro ano agrícola foi realizada na semana anterior ao plantio das mudas, aplicando-se $100 \mathrm{~kg} / \mathrm{ha}$ de $\mathrm{P}_{2} \mathrm{O}_{5}$ e $60 \mathrm{~kg} / \mathrm{ha}$ de $\mathrm{K}_{2} \mathrm{O}$, seguida de gradagem leve para incorporação; no ano subsequente, no mesmo período, aplicou-se, em superfície, $80 \mathrm{~kg} / \mathrm{ha}$ de $\mathrm{P}_{2} \mathrm{O}_{5}$ e $60 \mathrm{~kg} / \mathrm{ha}$ de $\mathrm{K}_{2} \mathrm{O}$. Para as adubações fosfatada e potássica, bem como para a correção da acidez, seguiu-se a recomendação da Comissão Brasileira de Química e Fertilidade do Solo- RS/SC (Manual..., 2004), para gramíneas perenes de estação quente. Para o N, usou-se ureia, sendo a quantidade total dividida em cinco aplicações por ano. No primeiro ano agrícola, as aplicações foram feitas 20 dias após o plantio das mudas e após a realização do primeiro, segundo, terceiro e quarto cortes da forragem; para o segundo ano, as aplicações foram realizadas após o primeiro, segundo, terceiro, quarto e quinto cortes da forragem.

Em setembro de 2014, foi realizada a implantação da gramínea, utilizando-se mudas de "capim-bermuda" (Cynodon dactylon L. Pers.) cv. Coastcross-1, maduras e dotadas de raízes, plantadas em covas de aproximadamente $10 \mathrm{~cm}$ de profundidade, espaçadas a cada $0,5 \mathrm{~m}$. Para inoculação das mudas, nos respectivos tratamentos, foi utilizado o produto comercial AzoTotal $^{\circledR}$ (inoculante líquido composto de cultura pura de bactérias Azospirillum brasilense, estirpes Ab-V5 e Ab-V6, com concentração de 2,0 x $10^{8} \mathrm{UFC} / \mathrm{mL}$; Total Biotecnologia, Brasil); fez-se a diluição do produto, na proporção de 0,5 1 de inoculante para cada 199,5 1 de água. A aplicação da calda foi realizada com o uso de pulverizador costal, diretamente na muda colocada na cova, antes de esta ser coberta com solo, utilizando-se uma proporção de 2001 de calda/ha. Para os tratamentos com inoculação no segundo ano agrícola, empregou-se a mesma proporção de inoculante do primeiro ano, com aplicação na parte aérea das plantas no final do mês de setembro de 2015.

O manejo foi realizado sob regime de corte, sendo efetuado com a altura de dossel forrageiro de aproximadamente $25 \mathrm{~cm}$. Em cada parcela, era realizado um corte em local aleatório, a $7 \mathrm{~cm}$ do solo (Ziech et al., 2016), utilizando-se um quadrado de $0,25 \mathrm{~m}^{2}$, o que caracterizava a massa de forragem. As amostras eram pesadas e separadas para determinação da composição botânica da forragem e morfológica da Coastcross-1 (lâmina foliar e colmo + bainha). Após a separação, os componentes foram secos em estufa de ar forçado a $55^{\circ} \mathrm{C}$, até peso constante para determinação da matéria seca (MS). Após a coleta das amostras, fez-se um corte $(7 \mathrm{~cm}$ do solo) do material remanescente, uniformizando as parcelas. A forragem cortada foi retirada das parcelas experimentais.

Foram realizados 14 cortes, com intervalo médio de 44 dias. No primeiro ano, foram realizados quatro cortes no período primavera-verão (43 dias de intervalo médio) e três cortes no outonoinverno (53 dias de intervalo médio). O último corte, em agosto, deu-se devido às condições meteorológicas atípicas para a região, com temperaturas elevadas (Fig. 1). No segundo ano, foram realizados cinco cortes no período primavera-verão (43 dias de intervalo médio) e dois no outono (37 dias de intervalo médio).

Os componentes morfológicos da Coastcross-1 foram moídos em moinho do tipo "Willey" e acondicionados na forma de amostra composta, misturando-se inicialmente as amostras de 
lâmina foliar e de colmo + bainha de cada parcela, do mesmo corte e, posteriormente, as amostras dos cortes, de acordo com os períodos (primavera-verão e outono-inverno, do primeiro ano; e primavera-verão e outono, do segundo ano). Em laboratório, foi determinada a MS total, em estufa a $105^{\circ} \mathrm{C}$, durante 16 horas. Foram realizadas análises para determinação da proteína bruta (PB), pelo método Kjeldahl (Official..., 1995), e digestibilidade in situ da matéria orgânica (DISMO), segundo Mehrez e Orskov (1977). A estimativa dos teores de nutrientes digestíveis totais (NDT) foi obtida pelo produto entre a porcentagem de matéria orgânica e a DISMO, dividido por 100 (Barber et al., 1984).

A taxa de produção de forragem foi calculada pelo quociente entre a massa de forragem e os dias de intervalo entre cortes. Para o cálculo da produção de PB da Coastcross-1, primeiramente se obteve a taxa de produção da Coastcross-1, multiplicando-se a taxa de produção de forragem pela porcentagem de participação da Coastcross1 na massa de forragem, dividida por 100. Então, multiplicou-se pelo teor de PB, dividido por 100 . Para a produção de NDT, usou-se a mesma metodologia de cálculo, valendo-se do NDT estimado.

O delineamento experimental utilizado foi o de blocos ao acaso, distribuído em esquema fatorial (inoculação x níveis de adubo x períodos do ano) com três repetições (parcelas). Os dados foram submetidos à análise de variância, por meio do procedimento MIXED. O efeito dos fatores e o de suas interações foram submetidos ao teste $\mathrm{T}$ de Student para a comparação de médias, em nível de $5 \%$ de probabilidade ao erro, desprotegidos pelo teste F. As matrizes de covariância utilizadas foram escolhidas pelo menor valor de AIC (Akaike's Information Criteria). Os erros foram submetidos ao teste de normalidade. As análises foram realizadas com auxílio do pacote estatístico Statistical Analysis System (SAS), versão 3.5.

Foi utilizado o seguinte modelo estatístico: $\mathrm{Y}_{\mathrm{ijkl}}=$ $\mathrm{m}+\mathrm{T}_{\mathrm{i}}+\mathrm{D}_{\mathrm{j}}+\mathrm{P}_{\mathrm{k}}+\mathrm{T}_{\mathrm{i}} \mathrm{D}_{\mathrm{j}}+\mathrm{T}_{\mathrm{i}} \mathrm{P}_{\mathrm{k}}+\mathrm{D}_{\mathrm{j}} \mathrm{P}_{\mathrm{k}}+\mathrm{T}_{\mathrm{i}} \mathrm{D}_{\mathrm{j}} \mathrm{P}_{\mathrm{k}}+$ $\mathrm{B}_{1}+\mathrm{B}_{\mathrm{l}}\left(\mathrm{T}_{\mathrm{i}} \mathrm{D}_{\mathrm{j}}\right)+\varepsilon_{\mathrm{ijk} \mathrm{l}}$, em que: $\mathrm{Y}_{\mathrm{ijkl}}$ representa as variáveis dependentes; $m$ é a média de todas as observações; $\mathrm{T}_{\mathrm{i}}$ é o efeito do uso da inoculação (i=3); $\mathrm{D}_{\mathrm{j}}$, é o efeito dos níveis de $\mathrm{N}(\mathrm{j}=3) ; \mathrm{P}_{\mathrm{k}}$, é o efeito dos períodos $(\mathrm{k}=4) ; \mathrm{T}_{\mathrm{i}} \mathrm{D}_{\mathrm{j}}$ é a interação entre inoculação e doses de $\mathrm{N} ; \mathrm{T}_{\mathrm{i}} \mathrm{P}_{\mathrm{k}}$ é a interação entre inoculação e períodos; $\mathrm{D}_{\mathrm{j}} \mathrm{P}_{\mathrm{k}}$ é a interação doses de $\mathrm{N}$ e períodos; $\mathrm{T}_{\mathrm{i}} \mathrm{D}_{\mathrm{j}} \mathrm{P}_{\mathrm{k}}$ é a interação entre inoculação, doses de $\mathrm{N}$ e períodos; $\mathrm{B}_{1}$ é o efeito dos blocos $(l=3) ; B_{1}\left(T_{i} D_{j}\right)$ é o efeito de blocos dentro da interação inoculação $\mathrm{x}$ níveis de $\mathrm{N}$ (erro a) e $\varepsilon_{\mathrm{ijkl}}$ é o efeito residual (erro b). $\mathrm{O}$ efeito referente aos anos agrícolas não está contemplado no modelo estatístico, pelo fato de o primeiro ano se referir à implantação da gramínea, optando-se pela discussão entre os períodos.

\section{RESULTADOS E DISCUSSÃO}

As alturas do dossel forrageiro (Tab. 1) verificadas no momento dos cortes, com média de $26 \mathrm{~cm}$, ficaram próximas da almejada, de $25 \mathrm{~cm}$. Diferenças $(\mathrm{P} \leq 0,05)$ foram observadas em todos os períodos quando não inoculadas, com maiores valores na dose de $200 \mathrm{~kg} / \mathrm{ha} /$ ano de $\mathrm{N}$, comparativamente ao não adubado com N. Nas inoculadas, foi verificada diferença apenas no primeiro período avaliado, com o mesmo padrão de resposta das não inoculadas.

Com relação à taxa de produção de forragem (Tab. 1), na comparação dos valores obtidos sem fornecimento de adubo nitrogenado, houve diferença $(\mathrm{P} \leq 0,05)$ nos quatro períodos em que os cortes foram agrupados. Nos três primeiros períodos, foram registrados valores superiores quando submetidos à inoculação. No outono do segundo ano, apenas no tratamento que foi inoculado nos dois anos houve maior disponibilidade de forragem em relação ao não inoculado. Esses resultados apontam que houve efeito positivo da inoculação com A. brasilense, quando não associada à adubação nitrogenada, possivelmente devido à sua ação como promotora do crescimento vegetal, por meio da fixação biológica de nitrogênio e da produção de fitormônios (Hungria et al., 2010; Lana et al., 2012).

Comparando-se os diferentes níveis de $\mathrm{N}$, notase maior distanciamento dos valores quando não inoculados. Para os inoculados, houve menor variabilidade, destacando-se que, no outonoinverno do primeiro ano, a taxa de produção de forragem foi igual em todos os níveis de $\mathrm{N}$, com valor médio de $29 \mathrm{~kg} / \mathrm{ha} / \mathrm{dia}$ de $\mathrm{MS}$. Ziech et al. (2016) ao avaliarem Coastcross-1 adubada com $80 \mathrm{~kg} / \mathrm{ha} /$ ano de $\mathrm{N}$, obtiveram valor superior, de $44 \mathrm{~kg} / \mathrm{ha} / \mathrm{dia}$ de $\mathrm{MS}$, para o outono-inverno do ano de implantação. 
Tabela 1. Altura do dossel forrageiro, taxa de produção de forragem e participação da Coastcross-1 inoculada com Azospirillum brasilense e submetida a diferentes doses de adubo nitrogenado. Santa Maria

\begin{tabular}{|c|c|c|c|c|c|c|}
\hline \multirow{3}{*}{ Doses N (kg) } & \multicolumn{2}{|c|}{ Períodos ano 1} & \multicolumn{2}{|c|}{ Períodos ano 2} & \multirow[t]{2}{*}{ Média } & \multirow[t]{2}{*}{$\mathrm{CV}(\%)$} \\
\hline & Pri - Ver ${ }^{1}$ & Out - Inv ${ }^{2}$ & Pri $-\mathrm{Ver}^{3}$ & $\mathrm{Out}^{4}$ & & \\
\hline \multirow{2}{*}{\multicolumn{7}{|c|}{$\begin{array}{c}\text { Altura do dossel forrageiro }(\mathrm{cm}) \\
\text { Não inoculada }\end{array}$}} \\
\hline & & & & & & \\
\hline 0 & $23^{\mathrm{D}}$ & $22^{\mathrm{B}}$ & $25^{\mathrm{B}}$ & $23^{\mathrm{C}}$ & 23 & 7,2 \\
\hline 100 & $26^{\mathrm{ABCD}}$ & $28^{\mathrm{A}}$ & $27^{\mathrm{AB}}$ & $25^{\mathrm{ABC}}$ & 26 & 5,1 \\
\hline 200 & $28^{\mathrm{AB}}$ & $29^{\mathrm{A}}$ & $29^{\mathrm{A}}$ & $29^{\mathrm{A}}$ & 29 & 3,7 \\
\hline \multicolumn{7}{|c|}{ Inoculada no primeiro ano } \\
\hline 0 & $24^{\mathrm{BCD}}$ & $25^{\mathrm{AB}}$ & $26^{\mathrm{AB}}$ & $23^{\mathrm{C}}$ & 24 & 5,6 \\
\hline 100 & $28^{\mathrm{ABCa}}$ & $26^{\mathrm{ABab}}$ & $27^{\mathrm{ABa}}$ & $24^{\mathrm{BCb}}$ & 26 & 5,4 \\
\hline 200 & $29^{\mathrm{A}}$ & $28^{\mathrm{A}}$ & $29^{\mathrm{A}}$ & $27^{\mathrm{ABC}}$ & 28 & 6,6 \\
\hline \multicolumn{7}{|c|}{ Inoculada no primeiro e no segundo ano } \\
\hline 0 & $24^{\mathrm{CD}}$ & $24^{\mathrm{AB}}$ & $26^{\mathrm{AB}}$ & $26^{\mathrm{ABC}}$ & 25 & 5,4 \\
\hline 100 & $27^{\mathrm{ABCD}}$ & $26^{\mathrm{AB}}$ & $26^{\mathrm{AB}}$ & $27^{\mathrm{ABC}}$ & 26 & 8,3 \\
\hline 200 & $29^{\mathrm{A}}$ & $27^{\mathrm{A}}$ & $27^{\mathrm{AB}}$ & $28^{\mathrm{AB}}$ & 28 & 5,2 \\
\hline $\mathrm{CV}(\%)$ & 9,4 & 11,5 & 8,9 & 10,7 & & \\
\hline \multicolumn{7}{|c|}{ Taxa de produção de forragem (kg de MS/ha/dia) ${ }^{* 5}$} \\
\hline & & & inoculada & & & \\
\hline 0 & $28,7^{\mathrm{Ea}}$ & $20,7^{\mathrm{Cb}}$ & $32,9^{\mathrm{Da}}$ & $21,2^{\mathrm{Db}}$ & 27,2 & 11,1 \\
\hline 100 & $38,9^{\mathrm{CDa}}$ & $23,4^{\mathrm{BCc}}$ & $40,7^{\mathrm{Ca}}$ & $33,0^{\mathrm{BCb}}$ & 34,9 & 8,5 \\
\hline 200 & $46,5^{\mathrm{ABa}}$ & $30,4^{\mathrm{Ab}}$ & $48,8^{\mathrm{ABa}}$ & $36,6^{\mathrm{ABCb}}$ & 41,9 & 7,1 \\
\hline \multicolumn{7}{|c|}{ Inoculada no primeiro ano } \\
\hline 0 & $36,7^{\mathrm{Da}}$ & $29,4^{\mathrm{ABb}}$ & $41,4^{\mathrm{Ca}}$ & $28,1^{\mathrm{CDb}}$ & 35,4 & 8,5 \\
\hline 100 & $44,9^{\mathrm{ABCa}}$ & $26,9^{\mathrm{ABb}}$ & $42,0^{\mathrm{BCa}}$ & $36,3^{\mathrm{ABCab}}$ & 38,2 & 7,7 \\
\hline 200 & $49,5^{\mathrm{Aa}}$ & $30,5^{\mathrm{Ab}}$ & $51,5^{\mathrm{Aa}}$ & $39,8^{\mathrm{ABab}}$ & 44,2 & 6,7 \\
\hline \multicolumn{7}{|c|}{ Inoculada no primeiro e no segundo ano } \\
\hline 0 & $36,6^{\mathrm{Db}}$ & $27,0^{\mathrm{ABc}}$ & $42,7^{\mathrm{BCa}}$ & $33,0^{\mathrm{BCb}}$ & 35,8 & 8,3 \\
\hline 100 & $42,1^{\mathrm{BCDa}}$ & $27,4^{\mathrm{ABb}}$ & $41,3^{\mathrm{Ca}}$ & $41,8^{\mathrm{ABa}}$ & 38,0 & 7,6 \\
\hline 200 & $51,0^{\mathrm{Aa}}$ & $32,5^{\mathrm{Ac}}$ & $54,5^{\mathrm{Aa}}$ & $43,3^{\mathrm{Ab}}$ & 46,5 & 6,4 \\
\hline $\mathrm{CV}(\%)$ & 2,8 & 4,6 & 2,9 & 6,0 & & \\
\hline \multicolumn{7}{|c|}{ Coastcross-1 $(\%)^{* 6}$} \\
\hline & & & inoculada & & & \\
\hline 0 & $35,6^{\mathrm{Bb}}$ & $52,8^{\mathrm{Ba}}$ & $56,4^{\mathrm{Ba}}$ & $47,6^{\mathrm{Bab}}$ & 48,1 & 4,5 \\
\hline 100 & $46,4^{\mathrm{ABb}}$ & $63,9^{\mathrm{ABa}}$ & $54,4^{\mathrm{Bab}}$ & $45,2^{\mathrm{Bb}}$ & 52,4 & 3,9 \\
\hline 200 & $46,7^{\mathrm{ABb}}$ & $71,0^{\mathrm{Aa}}$ & $66,7^{\mathrm{ABa}}$ & $53,7^{\mathrm{ABb}}$ & 59,5 & 3,6 \\
\hline \multicolumn{7}{|c|}{ Inoculada no primeiro ano } \\
\hline 0 & $52,7^{\mathrm{Ab}}$ & $65,5^{\mathrm{ABa}}$ & $57,0^{\mathrm{ABab}}$ & $59,7^{\mathrm{ABab}}$ & 58,7 & 2,6 \\
\hline 100 & $47,5^{\mathrm{ABc}}$ & $71,2^{\mathrm{Aa}}$ & $60,2^{\mathrm{ABab}}$ & $50,5^{\mathrm{Bbc}}$ & 57,3 & 4,5 \\
\hline 200 & $55,6^{\mathrm{Ab}}$ & $68,5^{\mathrm{ABa}}$ & $61,9^{\mathrm{ABab}}$ & $58,1^{\mathrm{ABab}}$ & 61,0 & 4,8 \\
\hline \multicolumn{7}{|c|}{ Inoculada no primeiro e no segundo ano } \\
\hline 0 & $54,0^{\mathrm{Ab}}$ & $68,0^{\mathrm{ABa}}$ & $69,2^{\mathrm{Aa}}$ & $66,4^{\mathrm{Aa}}$ & 64,4 & 3,0 \\
\hline 100 & $45,9^{\mathrm{ABc}}$ & $67,6^{\mathrm{ABa}}$ & $62,2^{\mathrm{ABab}}$ & $51,9^{\mathrm{ABbc}}$ & 56,9 & 3,1 \\
\hline 200 & $52,5^{\mathrm{Ab}}$ & $65,1^{\mathrm{ABa}}$ & $64,1^{\mathrm{ABab}}$ & $56,0^{\mathrm{ABab}}$ & 59,4 & 3,1 \\
\hline $\mathrm{CV}(\%)$ & 6,1 & 4,5 & 5,0 & 7,2 & & \\
\hline
\end{tabular}

Médias seguidas por letras distintas, maiúsculas na coluna e minúsculas na linha, diferem entre si pelo teste $\mathrm{T}$ de Student $(\mathrm{P} \leq 0,05)$. ${ }^{*}$ Coleta das amostras a $7 \mathrm{~cm}$ do solo. ${ }^{1}$ Quatro cortes; ${ }^{2}$ três cortes; ${ }^{3}$ cinco cortes; ${ }^{4}$ dois cortes; ${ }^{5}$ considerada toda massa de forragem; ${ }^{6}$ participação da Coastcross-1 na massa de forragem; Pri= primavera; Ver= verão; Out= outono; Inv= inverno; $\mathrm{CV}=$ coeficiente de variação.

Comparando-se as taxas de produção de forragem obtidas nos diferentes períodos avaliados, os maiores valores foram registrados na primavera-verão dos dois anos. Ziech et al. (2016) registraram aumento na taxa de acúmulo de forragem do ano de implantação, para o segundo ano de avaliação. No presente trabalho, apenas quando reinoculada e não adubado com $\mathrm{N}$, houve aumento, o que denota a necessidade da reinoculação. Salienta-se a importância da produção de forragem no outono-inverno, especialmente no período outonal, quando as 
forrageiras de ciclo hibernal muitas vezes ainda não estão aptas para o uso, com destaque para a disponibilidade nas inoculadas.

Quanto à participação da Coastcross-1 na massa de forragem (Tab. 1), na fase inicial de estabelecimento da cultura (primavera-verão do primeiro ano), na ausência de adubo nitrogenado, os valores foram superiores $(\mathrm{P} \leq 0,05)$ quando inoculadas. Também houve efeito no segundo ano, nos dois períodos avaliados, com participação superior da Coastcross-1 quando submetida à reinoculação, em relação à não inoculada. $\mathrm{O}$ melhor estabelecimento da gramínea quando inoculada pode estar ligado ao maior desenvolvimento do sistema radicular, com aumento da área superficial das raízes, maior absorção de nutrientes e melhor desenvolvimento como um todo da planta. Esse estímulo ao crescimento de raízes com a inoculação é relatado por diversos autores para gramíneas como o milho e o trigo (Hungria et al., 2010; Lana et al., 2012) e está associado à produção de fitormônios pelas bactérias.

Para a participação da Coastcross-1 na massa de forragem ao longo dos dois anos avaliados, os menores valores registrados, na primavera-verão do primeiro ano, ocorreram por esta ser a fase inicial de estabelecimento da gramínea. Os valores elevados encontrados no outono-inverno do mesmo ano devem-se principalmente ao corte realizado no inverno, que, com a ocorrência de temperaturas acima das médias normais (Fig. 1), propiciou o desenvolvimento da Coastcross-1. A participação média da Coastcross-1, de 62,4\%, observada na primavera-verão do segundo ano, quando inoculada, é semelhante à registrada, no verão, por Aguirre et al. (2014), de 61,7\%, ao avaliarem pasto de Coastcross- 1 em consórcio com trevo vesiculoso e adubado com $100 \mathrm{~kg} / \mathrm{ha} / \mathrm{ano}$ de $\mathrm{N}$.

Além da Coastcross-1, compunham a massa de forragem espécies de crescimento espontâneo, como o capim-setária (Setaria spp.), o Paspalum conjugatum, a grama-paulista (Cynodon dactylon), o capim-das-roças (Paspalum urvillei Steud.), o capim- pelo-de-porco (Piptochaetium montevidense) e o azevém provindo de ressemeadura natural na área.

Não houve efeito da inoculação sobre a composição morfológica da Coastcross-1. Houve, no entanto, efeito $(\mathrm{P} \leq 0,05)$ da adubação nitrogenada (Tab. 2), com aumento da participação da fração colmo + bainha $\mathrm{e}$ consequente diminuição de lâminas foliares, quando os pastos foram submetidos à adubação nitrogenada, e também com a elevação da dose aplicada. Isto ocorre porque a adubação nitrogenada implica maior desenvolvimento da gramínea, com aumento na participação de colmos na sua composição morfológica (Oliveira et al., 2011; Aguirre et al., 2014). No primeiro período de avaliação, esse maior desenvolvimento é confirmado pelas diferenças nas alturas dos dosséis (Tab. 1), encontradas independentemente da inoculação. As maiores variabilidades na composição morfológica ao longo das avaliações foram observadas para a Coastcross-1 dos pastos adubados com $200 \mathrm{~kg} / \mathrm{ha} / \mathrm{ano}$ de $\mathrm{N}$.

Para os teores de PB da Coastcross-1 (Tab. 3), houve diferença $(\mathrm{P} \leq 0,05)$ em três dos quatro períodos. O teor de PB da Coastcross-1, quando não inoculada e adubada com $200 \mathrm{~kg} / \mathrm{ha} / \mathrm{ano}$ de $\mathrm{N}$, foi maior $(\mathrm{P} \leq 0,05)$ que o daquelas inoculadas e com igual adubação nitrogenada, tanto na primavera-verão quanto no outono-inverno do primeiro ano. Na primavera-verão do segundo ano, também na dose de $200 \mathrm{~kg} / \mathrm{ha} /$ ano de $\mathrm{N}$, apenas o teor de PB da Coastcross-1 que foi reinoculada nesse período foi inferior ao da gramínea não inoculada. Lana et al. (2012), quando trabalharam com milho, observaram redução no teor de $\mathrm{N}$ foliar quando se associou a inoculação com $100 \mathrm{~kg} /$ ha de $\mathrm{N}$ em cobertura. No presente trabalho, esta dose de $\mathrm{N}$ não teve interação com a inoculação, apresentando redução com 200kg/ha/ano de N. Os autores relataram a necessidade de maiores estudos para compreender a contribuição da inoculação quando associada à adubação nitrogenada. No entanto, Hungria et al. (2016) obtiveram aumentos de $21,7 \%$ no teor de $\mathrm{N}$ em pastos de $B$. brizantha e $B$. ruziziensis, adubadas com $40 \mathrm{~kg} / \mathrm{ha}$ de $\mathrm{N}$, quando inoculados com A. brasilense (AbV5 e Ab-V6). 
Valor nutritivo...

Tabela 2. Efeito da interação de diferentes doses de adubação nitrogenada e períodos de avaliação sobre a composição morfológica da Coastcross-1. Santa Maria - RS, 2014-2016

\begin{tabular}{|c|c|c|c|c|c|c|}
\hline \multirow{2}{*}{$\begin{array}{c}\text { Doses N } \\
(\mathrm{kg})\end{array}$} & \multicolumn{2}{|c|}{ Períodos ano 1} & \multicolumn{2}{|c|}{ Períodos ano 2} & \multirow[t]{2}{*}{ Média } & \multirow[t]{2}{*}{$\mathrm{CV}(\%)$} \\
\hline & Pri - Ver ${ }^{1}$ & Out - Inv ${ }^{2}$ & Pri - Ver ${ }^{3}$ & Out $^{4}$ & & \\
\hline \multicolumn{7}{|c|}{ Lâmina foliar (\%)* } \\
\hline 0 & $57,9^{\mathrm{Aa}}$ & $54,9^{\mathrm{Ab}}$ & $55,2^{\mathrm{Ab}}$ & $54,3^{\mathrm{Ab}}$ & 55,6 & 1,9 \\
\hline 100 & $54,1^{\mathrm{Ba}}$ & $53,2^{\mathrm{Aa}}$ & $54,4^{\mathrm{ABa}}$ & $45,9^{\mathrm{Bb}}$ & 51,9 & 2,0 \\
\hline 200 & $50,6^{\mathrm{Cb}}$ & $50,4^{\mathrm{Bb}}$ & $53,6^{\mathrm{Ba}}$ & $45,1^{\mathrm{Bc}}$ & 49,9 & 2,1 \\
\hline $\mathrm{CV}(\%)$ & 1,4 & 1,5 & 1,1 & 2,7 & & \\
\hline \multicolumn{7}{|c|}{ Colmo + bainha da folha $(\%)^{*}$} \\
\hline 0 & $42,1^{\mathrm{Cb}}$ & $45,1^{\mathrm{Ba}}$ & $44,8^{\mathrm{Ba}}$ & $45,7^{\mathrm{Ba}}$ & 44,4 & 2,3 \\
\hline 100 & $45,9^{\mathrm{Bb}}$ & $46,8^{\mathrm{Bb}}$ & $45,6^{\mathrm{ABb}}$ & $54,1^{\mathrm{Aa}}$ & 48,1 & 2,2 \\
\hline 200 & $49,4^{\mathrm{Ab}}$ & $49,6^{\mathrm{Ab}}$ & $46,4^{\mathrm{Ac}}$ & $54,9^{\mathrm{Aa}}$ & 50,1 & 2,1 \\
\hline $\mathrm{CV}(\%)$ & 1,7 & 1,7 & 1,4 & 2,5 & & \\
\hline
\end{tabular}

Médias seguidas por letras distintas, maiúsculas na coluna e minúsculas na linha, diferem entre si pelo teste $\mathrm{T}$ de Student $(\mathrm{P} \leq 0,05)$. ${ }^{*}$ Coleta das amostras a $7 \mathrm{~cm}$ do solo. ${ }^{1}$ Quatro cortes; ${ }^{2}$ três cortes; ${ }^{3}$ cinco cortes; ${ }^{4}$ dois cortes; Pri $=$ primavera; Ver= verão; Out= outono; $\mathrm{Inv}=$ inverno; $\mathrm{CV}=$ coeficiente de variação.

Comparando-se os períodos, os maiores valores de PB foram encontrados no outono-inverno do primeiro ano, para todos os tratamentos, tendo se equiparado em alguns deles aos valores do outono do segundo ano. Padrão de resposta similar foi observado por Olivo et al. (2007), quando trabalharam com gramínea de ciclo estival (capim-elefante), com valores de 13,37 e $17,17 \%$ de PB, para os períodos estival e hibernal, respectivamente. Os autores relacionaram os resultados ao maior desenvolvimento das gramíneas tropicais no período estival, principalmente verão, com elevação da produção de forragem e, por conseguinte, da fibra em detergente neutro e consequente diminuição da PB.

Quanto à produção de $\mathrm{PB}$ (Tab. 3), foi observada diferença $(\mathrm{P} \leq 0,05)$ para a mesma dose de $\mathrm{N}$, apenas no outono do segundo ano de avaliação, na Coastcross-1 que não recebeu adubo nitrogenado, com maior valor para a gramínea reinoculada, comparativamente à não inoculada. Essa diferença está associada à maior taxa de produção e participação na massa de forragem neste período (Tab. 1).

As diferenças observadas para o teor de $\mathrm{PB}$, na dose de $200 \mathrm{~kg} / \mathrm{ha} / \mathrm{ano}$ de $\mathrm{N}$, não se repetiram para a produção de PB. Para a Coastcross-1 inoculada, a produção de PB foi igual em todos os níveis de adubo nitrogenado, exceto na primavera-verão do segundo ano, quando se observou diferença entre os níveis de $\mathrm{N}$ para a gramínea reinoculada nesse período. Esta similaridade evidencia a colaboração da inoculação nas doses mais baixas de adubo nitrogenado, especialmente quando não adubada com N.

Na comparação ao longo dos períodos avaliados, em seis dos nove tratamentos, diferenças $(\mathrm{P} \leq 0,05)$ para produção de $\mathrm{PB}$ foram registradas, sendo observados maiores valores no outonoinverno do primeiro ano e na primavera-verão do segundo. Esse resultado é justificado pelos maiores teores de $\mathrm{PB}$, no primeiro caso, e pela maior taxa de produção, no segundo (Tab. 1).

Para a DISMO e o NDT (Tab. 4), na Coastcross1 não submetida à adubação nitrogenada, foi observada diferença $(\mathrm{P} \leq 0,05)$ na primaveraverão do segundo ano, com maior valor quando foi reinoculada nesse período, comparativamente à que só foi inoculada no plantio. Possivelmente a reinoculação possa ter colaborado para elevar a digestibilidade da gramínea, associada à grande participação da Coastcross-1 na massa de forragem (Tab. 1). No outono do segundo ano, foi observada diferença para os valores de DISMO e NDT na Coastcross-1 adubada com $100 \mathrm{~kg} / \mathrm{ha} / \mathrm{ano}$ de $\mathrm{N}$, com valor superior na gramínea inoculada somente no primeiro ano, comparativamente à reinoculada no segundo ano. Segundo Oliveira et al. (2011), o aumento das doses de $\mathrm{N}$ causa aumento na digestibilidade da Coastcross-1, fato que não ocorreu no presente estudo. 
Tabela 3. Teores e produção de proteína bruta da Coastcross-1 inoculada com Azospirillum brasilense e submetida a diferentes doses de adubo nitrogenado. Santa Maria - RS, 2014-2016

\begin{tabular}{|c|c|c|c|c|c|c|}
\hline \multirow{2}{*}{$\begin{array}{c}\text { Doses N } \\
(\mathrm{kg})\end{array}$} & \multicolumn{2}{|c|}{ Períodos ano 1} & \multicolumn{2}{|c|}{ Períodos ano 2} & \multirow[t]{2}{*}{ Média } & \multirow[t]{2}{*}{$\begin{array}{l}\mathrm{CV} \\
(\%)\end{array}$} \\
\hline & Pri - Ver ${ }^{1}$ & Out - Inv ${ }^{2}$ & Pri - Ver ${ }^{3}$ & $\mathrm{Out}^{4}$ & & \\
\hline \multicolumn{7}{|c|}{ Proteína bruta da Coastcross- $1(\%)^{*}$} \\
\hline \multicolumn{7}{|c|}{ Não inoculada } \\
\hline 0 & $9,6^{\mathrm{Dc}}$ & $16,3^{\mathrm{Ba}}$ & $12,2^{\mathrm{BCb}}$ & $15,6^{\mathrm{a}}$ & 13,5 & 3,8 \\
\hline 100 & $11,2^{\mathrm{Bc}}$ & $16,9^{\mathrm{ABa}}$ & $12,0^{\mathrm{BCc}}$ & $14,9^{\mathrm{b}}$ & 13,8 & 3,7 \\
\hline 200 & $12,9^{\mathrm{Ab}}$ & $18,2^{\mathrm{Aa}}$ & $13,5^{\mathrm{Ab}}$ & $14,5^{\mathrm{b}}$ & 14,8 & 3,5 \\
\hline \multicolumn{7}{|c|}{ Inoculada no primeiro ano } \\
\hline 0 & $9,9^{\mathrm{CDc}}$ & $16,0^{\mathrm{Ba}}$ & $12,3^{\mathrm{BCb}}$ & $14,3^{\mathrm{ab}}$ & 13,1 & 3,9 \\
\hline 100 & $10,7^{\mathrm{BCc}}$ & $16,9^{\mathrm{ABa}}$ & $11,7^{\mathrm{BCc}}$ & $14,2^{\mathrm{b}}$ & 13,4 & 3,9 \\
\hline 200 & $11,6^{\mathrm{Bb}}$ & $16,4^{\mathrm{Ba}}$ & $12,7^{\mathrm{ABb}}$ & $14,7^{\mathrm{a}}$ & 13,9 & 3,7 \\
\hline \multicolumn{7}{|c|}{ Inoculada no primeiro e no segundo ano } \\
\hline 0 & $10,3^{\mathrm{CDc}}$ & $16,5^{\mathrm{Ba}}$ & $11,2^{\mathrm{Cc}}$ & $14,2^{\mathrm{b}}$ & 13,0 & 3,9 \\
\hline 100 & $10,9^{\mathrm{BCc}}$ & $17,7^{\mathrm{ABa}}$ & $11,4^{\mathrm{Cc}}$ & $14,6^{\mathrm{b}}$ & 13,7 & 3,8 \\
\hline 200 & $11,0^{\mathrm{BCc}}$ & $15,8^{\mathrm{Ba}}$ & $12,2^{\mathrm{BCbc}}$ & $13,8^{\mathrm{ab}}$ & 13,2 & 3,9 \\
\hline $\mathrm{CV}(\%)$ & 2,5 & 2,3 & 1,9 & 3,0 & & \\
\hline \multicolumn{7}{|c|}{ Produção de proteína bruta da Coastcross-1 (kg/ha/dia)* } \\
\hline \multicolumn{7}{|c|}{ Não inoculada } \\
\hline 0 & $1,0^{\mathrm{Bb}}$ & $1,8^{\mathrm{Ca}}$ & $2,4^{\mathrm{Ca}}$ & $1,6^{\mathrm{Bab}}$ & 1,8 & 13,0 \\
\hline 100 & $2,1^{\mathrm{AB}}$ & $2,5^{\mathrm{BC}}$ & $2,7^{\mathrm{C}}$ & $2,3^{\mathrm{AB}}$ & 2,4 & 7,7 \\
\hline 200 & $2,8^{\mathrm{Ab}}$ & $4,1^{\mathrm{Aa}}$ & $4,4^{\mathrm{Aa}}$ & $2,9^{\mathrm{Ab}}$ & 3,7 & 6,8 \\
\hline \multicolumn{7}{|c|}{ Inoculada no primeiro ano } \\
\hline 0 & $2,0^{\mathrm{ABb}}$ & $3,2^{\mathrm{ABCa}}$ & $3,0^{\mathrm{BCab}}$ & $2,4^{\mathrm{ABb}}$ & 2,7 & 9,4 \\
\hline 100 & $2,4^{\mathrm{ABab}}$ & $3,3^{\mathrm{ABCa}}$ & $3,0^{\mathrm{BCab}}$ & $2,3^{\mathrm{ABb}}$ & 2,8 & 9,0 \\
\hline 200 & $3,4^{\mathrm{A}}$ & $3,5^{\mathrm{AB}}$ & $4,1^{\mathrm{AB}}$ & $3,2^{\mathrm{A}}$ & 3,6 & 12,3 \\
\hline \multicolumn{7}{|c|}{ Inoculada no primeiro e no segundo ano } \\
\hline 0 & $2,1^{\mathrm{ABb}}$ & $3,1^{\mathrm{ABCa}}$ & $3,4^{\mathrm{ABCa}}$ & $3,1^{\mathrm{Aa}}$ & 2,9 & 5,6 \\
\hline 100 & $2,1^{\mathrm{ABb}}$ & $3,2^{\mathrm{ABCa}}$ & $3,0^{\mathrm{BCab}}$ & $3,1^{\mathrm{Aa}}$ & 2,8 & 8,6 \\
\hline 200 & $3,0^{\mathrm{A}}$ & $3,3^{\mathrm{ABC}}$ & $4,4^{\mathrm{A}}$ & $3,4^{\mathrm{A}}$ & 3,6 & 9,7 \\
\hline $\mathrm{CV}(\%)$ & 11,7 & 8,7 & 8,0 & 10,0 & & \\
\hline
\end{tabular}

Médias seguidas por letras distintas, maiúsculas na coluna e minúsculas na linha, diferem entre si pelo teste $\mathrm{T}$ de Student $(\mathrm{P} \leq 0,05)$. ${ }^{*}$ Coleta das amostras a $7 \mathrm{~cm}$ do solo. ${ }^{1}$ Quatro cortes; ${ }^{2}$ três cortes; ${ }^{3}$ cinco cortes; ${ }^{4}$ dois cortes; Pri= primavera; Ver= verão; Out= outono; Inv= inverno; $\mathrm{CV}=$ coeficiente de variação.

A Coastcross-1, quando inoculada, apresentou regularidade tanto para os valores de DISMO quanto nos teores de NDT, registrados ao longo dos dois anos avaliados. Essa estabilidade é interessante, na medida em que, quando for utilizada para pastejo, consegue-se ter um melhor equilíbrio energético da dieta dos animais ao longo dos períodos. Olivo et al. (2016) obtiveram valores de DISMO e NDT semelhantes aos do presente trabalho para pastos de Coastcross- 1 adubados com $150 \mathrm{~kg} / \mathrm{ha} /$ ano de $\mathrm{N}$, sendo de 63,7; 65,2 e 63,0\% de DISMO e de 58,$6 ; 56,9$ e $58,2 \%$ de NDT, para primavera, verão e outono, respectivamente. 
Tabela 4. Digestibilidade in situ da matéria orgânica, teor e produção de nutrientes digestíveis totais da Coastcross-1 inoculada com Azospirillum brasilense e submetida a diferentes doses de adubo nitrogenado. Santa Maria - RS, 2014-2016

\begin{tabular}{|c|c|c|c|c|c|c|}
\hline \multirow{2}{*}{ Doses N (kg) } & \multicolumn{2}{|c|}{ Períodos ano 1} & \multicolumn{2}{|c|}{ Períodos ano 2} & \multirow[t]{2}{*}{ Média } & \multirow[t]{2}{*}{$\mathrm{CV}(\%)$} \\
\hline & Pri - Ver ${ }^{1}$ & Out - Inv ${ }^{2}$ & Pri $-\mathrm{Ver}^{3}$ & $\mathrm{Out}^{4}$ & & \\
\hline \multicolumn{7}{|c|}{ Digestibilidade in situ da matéria orgânica da Coastcross-1 (\%)* } \\
\hline \multicolumn{7}{|c|}{ Não inoculada } \\
\hline 0 & $57,7^{\mathrm{C}}$ & $69,7^{\mathrm{Aa}}$ & $63,6^{\mathrm{ABb}}$ & $64,0^{\mathrm{ABab}}$ & 63,7 & 3,2 \\
\hline 100 & $63,8^{\mathrm{ab}}$ & $69,0^{\mathrm{ABa}}$ & $64,8^{\mathrm{ABab}}$ & $63,6^{\mathrm{ABb}}$ & 65,3 & 3,1 \\
\hline 200 & $60,8^{\mathrm{b}}$ & $65,4^{\mathrm{ABab}}$ & $66,5^{\mathrm{Aa}}$ & $60,8^{\mathrm{ABb}}$ & 63,4 & 3,2 \\
\hline \multicolumn{7}{|c|}{ Inoculada no primeiro ano } \\
\hline 0 & $57,1^{\mathrm{b}}$ & $67,2^{\mathrm{ABa}}$ & $61,3^{\mathrm{Bb}}$ & $61,3^{\mathrm{ABb}}$ & 61,6 & 3,3 \\
\hline 100 & 58,5 & $64,5^{\mathrm{AB}}$ & $65,0^{\mathrm{AB}}$ & $65,4^{\mathrm{A}}$ & 63,3 & 3,2 \\
\hline 200 & 62,3 & $67,1^{\mathrm{AB}}$ & $62,3^{\mathrm{AB}}$ & $64,7^{\mathrm{AB}}$ & 64,1 & 3,2 \\
\hline \multicolumn{7}{|c|}{ Inoculada no primeiro e no segundo ano } \\
\hline 0 & 61,7 & $65,4^{\mathrm{AB}}$ & $66,7^{\mathrm{A}}$ & $62,6^{\mathrm{AB}}$ & 64,1 & 3,2 \\
\hline 100 & 59,6 & $64,8^{\mathrm{AB}}$ & $64,1^{\mathrm{AB}}$ & $60,1^{\mathrm{B}}$ & 62,1 & 3,3 \\
\hline 200 & 62,2 & $64,3^{\mathrm{B}}$ & $63,5^{\mathrm{AB}}$ & $60,9^{\mathrm{AB}}$ & 62,7 & 3,3 \\
\hline $\mathrm{CV}(\%)$ & 3,2 & 1,7 & 1,7 & 1,7 & & \\
\hline \multicolumn{7}{|c|}{ Nutrientes digestíveis totais da Coastcross-1 (\%)* } \\
\hline \multicolumn{7}{|c|}{ Não inoculada } \\
\hline 0 & $53,6^{\mathrm{b}}$ & $63,7^{\mathrm{a}}$ & $59,0^{\mathrm{ABab}}$ & $59,2^{\mathrm{ABab}}$ & 58,9 & 3,2 \\
\hline 100 & 59,3 & 63,1 & $60.2^{\mathrm{AB}}$ & $58.5^{\mathrm{AB}}$ & 60,3 & 3.1 \\
\hline 200 & $56,5^{\mathrm{ab}}$ & $59,8^{\mathrm{ab}}$ & $61,7^{\mathrm{Aa}}$ & $56,2^{\mathrm{ABb}}$ & 58,5 & 3,2 \\
\hline \multicolumn{7}{|c|}{ Inoculada no primeiro ano } \\
\hline 0 & $53,3^{\mathrm{b}}$ & $61,7^{\mathrm{a}}$ & $56,9^{\mathrm{Bb}}$ & $56,4^{\mathrm{ABb}}$ & 57,1 & 3,3 \\
\hline 100 & 54,6 & 59,5 & $60,6^{\mathrm{AB}}$ & $60,6^{\mathrm{A}}$ & 58,8 & 3,2 \\
\hline 200 & 57,9 & 61,7 & $58,0^{\mathrm{AB}}$ & $60,2^{\mathrm{A}}$ & 59,5 & 3,2 \\
\hline \multicolumn{7}{|c|}{ Inoculada no primeiro e no segundo ano } \\
\hline 0 & 57,3 & 59,8 & $61,9^{\mathrm{A}}$ & $57,6^{\mathrm{AB}}$ & 59,2 & 3,2 \\
\hline 100 & 55,5 & 59,3 & $59,6^{\mathrm{AB}}$ & $55,5^{\mathrm{B}}$ & 57,5 & 3,3 \\
\hline 200 & 57,9 & 59,1 & $59,3^{\mathrm{AB}}$ & $56,6^{\mathrm{AB}}$ & 58,2 & 3,3 \\
\hline $\mathrm{CV}(\%)$ & 3,2 & 1,7 & 1,7 & 1,7 & & \\
\hline \multicolumn{7}{|c|}{ Produção de nutrientes digestíveis totais da Coastcross-1 (kg/ha/dia)* } \\
\hline \multicolumn{7}{|c|}{ Não inoculada } \\
\hline 0 & $5,4^{\mathrm{Cb}}$ & $7,2^{\mathrm{Bb}}$ & $11,3^{\mathrm{Da}}$ & $6,2^{\mathrm{Cb}}$ & 8,0 & 15,3 \\
\hline 100 & $10,8^{\mathrm{Bab}}$ & $9,4^{\mathrm{ABL}}$ & $13,5^{\mathrm{CDa}}$ & $9,1^{\mathrm{BCb}}$ & 11,2 & 8,1 \\
\hline 200 & $12,2^{\mathrm{Bb}}$ & $13,4^{\mathrm{Al}}$ & $20,0^{\mathrm{Aa}}$ & $11,0^{\mathrm{ABb}}$ & 15,1 & 5,6 \\
\hline \multicolumn{7}{|c|}{ Inoculada no primeiro ano } \\
\hline 0 & $10,2^{\mathrm{Bab}}$ & $12,1^{\mathrm{Aa}}$ & $13,6^{\mathrm{CDa}}$ & $9,5^{\mathrm{ABCb}}$ & 11,8 & 5,4 \\
\hline 100 & $12,0^{\mathrm{Bab}}$ & $11,4^{\mathrm{Ab}}$ & $15,8^{\mathrm{BCa}}$ & $9,9^{\mathrm{ABCc}}$ & 12,9 & 9,7 \\
\hline 200 & $16,2^{\text {Aab }}$ & $12,9^{\mathrm{Al}}$ & $18,6^{\mathrm{ABa}}$ & $12,2^{\mathrm{ABb}}$ & 15,7 & 7,8 \\
\hline \multicolumn{7}{|c|}{ Inoculada no primeiro e no segundo ano } \\
\hline 0 & $11,3^{\mathrm{Bb}}$ & $11,1^{\mathrm{Al}}$ & $18,3^{\mathrm{ABa}}$ & $12,8^{\mathrm{ABb}}$ & 13,9 & 4,9 \\
\hline 100 & $10,9^{\mathrm{Bb}}$ & $11,1^{\mathrm{Al}}$ & $15,4^{\mathrm{BCa}}$ & $12,2^{\mathrm{ABab}}$ & 12,7 & 8,2 \\
\hline 200 & $15,8^{\mathrm{Aab}}$ & $12,6^{\mathrm{Al}}$ & $21,1^{\mathrm{Aa}}$ & $13,7^{\mathrm{Ab}}$ & 16,6 & 6,9 \\
\hline $\mathrm{CV}(\%)$ & 10,0 & 10,3 & 7,1 & 10,7 & & \\
\hline
\end{tabular}

Médias seguidas por letras distintas, maiúsculas na coluna e minúsculas na linha, diferem entre si pelo teste $\mathrm{T}$ de Student $(\mathrm{P} \leq 0,05)$. *Coleta das amostras a $7 \mathrm{~cm}$ do solo. ${ }^{1}$ Quatro cortes; ${ }^{2}$ três cortes; ${ }^{3}$ cinco cortes; ${ }^{4}$ dois cortes; Pri= primavera; Ver= verão; Out= outono; $\mathrm{Inv}=$ inverno; $\mathrm{CV}=$ coeficiente de variação.

Diferentemente do teor de NDT, para a produção de NDT (Tab. 4) houve diferença $(\mathrm{P} \leq 0,05)$ em todos os períodos avaliados. Comparando-se a Coastcross-1 sem adubação nitrogenada, fica evidenciado o efeito da inoculação na produção de NDT, com valores superiores em todos os períodos para a gramínea inoculada nos dois anos agrícolas, quando comparada à não inoculada. Para a Coastcross-1 inoculada somente no primeiro ano, a produção de NDT foi superior nos dois primeiros períodos em relação à não inoculada. Analisando-se a média da produção de NDT do tratamento com inoculação em ambos os anos e sem adubo nitrogenado, esta 
é 42,4\% maior que no não inoculado. Para a dose $200 \mathrm{~kg} / \mathrm{ha} /$ ano de $\mathrm{N}$, houve diferença $(\mathrm{P} \leq 0,05)$ na primavera-verão do primeiro ano, com valores superiores para as gramíneas inoculadas em relação à não inoculada.

Ao longo dos períodos avaliados, verificou-se padrão de resposta similar da Coastcross-1 para a produção de NDT, com maiores valores na primavera-verão do segundo ano, seguido do mesmo período no primeiro ano, época de maior desenvolvimento da gramínea em estudo (Oliveira et al., 2011; Aguirre et al., 2014).

\section{CONCLUSÕES}

A inoculação com A. brasilense, estirpes Ab-V5 e Ab-V6, quando não associada à adubação nitrogenada, eleva a taxa de produção de forragem, proporciona maior participação da Coastcross-1 no dossel forrageiro e aumenta a produção de energia (NDT) na Coastcross-1, sendo necessária a reinoculação anual. Quando associada à adubação de $200 \mathrm{~kg} / \mathrm{ha} / \mathrm{ano}$ de N, a inoculação acarreta redução do teor de PB da Coastcross-1, sem afetar, no entanto, a produção de PB.

\section{REFERÊNCIAS}

AGUIRRE, P.F.; OLIVO, C.J.; SIMONETTI, G.D. et al. Produtividade de pastagens de Coastcross-1 em consórcio com diferentes leguminosas de ciclo hibernal. Cienc. Rural, v.44, p.2265-2272, 2014.

BANCO de dados meteorológicos para ensino e pesquisa. Dados mensais. Estação Meteorológica de Santa Maria - cód. A803, 2014-2016. Santa Maria: INMET, 2016.

BARBER, W.P.B.; ADAMSON, A.H.; ALTMAN, J.F.B. New methods of feed evaluation. In: HARESIGN, W.; COLE, D.J.A. (Eds.). Recent advances in animal nutrition. London: Butterworths, 1984. p.161-176.

HUNGRIA, M.; CAMPO, R.J.; SOUZA, E.M.; PEDROSA, F.O. Inoculation with selected strains of Azospirillum brasilense and $A$. lipoferum improves yields of maize and wheat in Brazil. Plant Soil, v.331, p.413-425, 2010.
HUNGRIA, M.; NOGUEIRA, M.A.; ARAUJO, R.S. Inoculation of Brachiaria spp. with the plant growth-promoting bacterium Azospirillum brasilense: An environment-friendly component in the reclamation of degraded pastures in the tropics. Agric. Ecosyst. Environ., v.221, p.125131, 2016.

KÖPPEN, W. Climatologia. Buenos Aires: Panamericana, 1948. 478p.

LANA, M.C.; DARTORA, J.; MARINI, D.; HANN, J.E. Inoculation with Azospirillum, associated with nitrogen fertilization in maize. Rev. Ceres, v.59, p.399-405, 2012.

MANUAL de adubação e calagem para os Estados do Rio Grande do Sul e de Santa Catarina. 10.ed. Porto Alegre: SBCS-CQFS, 2004. 400p.

MEHREZ, A.Z.; ORSKOV, E.R.A. Study of the artificial fibre bag technique for determining the digestibility of feed in the rumen. J. Agric. Sci., v.88, p.645-650, 1977.

OFFICIAL methods of analysis. 16.ed. Washington: AOAC, 1995. v.2, 1015p.

OLIVEIRA, M.A.; PEREIRA, O.G.; RIBEIRO, K.G. et al. Produção e valor nutritivo do capimcoastcross sob doses de nitrogênio e idades de rebrotação. Arq. Bras. Med. Vet. Zootec., v.63, p.694-703, 2011.

OLIVO, C. J.; CHARÃO, P.L.; PEREIRA, L.E.T. et al. Produtividade e valor nutritivo de pasto de capim-elefante manejado sob princípios agroecológicos. Rev. Bras. Zootec., v.36, p.7291735, 2007.

OLIVO, C. J.; SANTOS, J.C.; QUATRIN, M.P. et al. Forage mass and nutritive value of bermuda grass mixed to forage peanut or common vetch. Acta Sci. Anim. Sci., v.38, p.255260, 2016.

STRECK, E.V.; KÄMPF, N.; DALMOLIN, R.S.D. et al. Solos do Rio Grande do Sul. 2.ed. Porto Alegre: EMATER/RS, 2008. 222p.

ZIECH, M.F.; OLIVO, C.J.; ZIECH, A.R.D. et al. Responses of Cynodon pastures mixed with forage peanut in southwestern Paraná, Brazil. Semin. Cienc. Agrar., v.37, p.4193-4202, 2016. 